\title{
Promoting Walkability in Streets: Analytical Study of Salem Street, Sulaimani, Iraq
}

\author{
Daban Abdullah Salam \\ Engineering Department \\ Kurdistan Institution for Strategic Studies and Scientific Research, Kurdistan \\ Sulaimani, Iraq \\ daban.salam@kissr.edu.krd
}

\author{
Binaee Yaseen Raof \\ Department of City Planning \\ Technical College of Engineering \\ Sulaimani Polytechnic University \\ Sulaimani, Iraq \\ binaee.yaseen@spu.edu.iq
}

\author{
Sara Dhiaadin Bahaadin \\ Department of City Planning \\ Technical College of Engineering \\ Sulaimani Polytechnic University \\ Sulaimani, Iraq \\ sara.bahaadin@spu,.edu.iq
}

\begin{tabular}{|c|}
\hline Article Info \\
\hline $\begin{array}{l}\text { Volume } 5-\text { Issue } 1 \\
\text { June } 2020\end{array}$ \\
\hline $\begin{array}{l}\text { DOI: } \\
10.24017 / \text { science. } 2020.1 .6\end{array}$ \\
\hline Article history: \\
\hline $\begin{array}{l}\text { Received } \\
\text { Accepted }\end{array}$ \\
\hline
\end{tabular}

Keywords:

Walkability, promoting walking, sustainable transportation, Sulaimani city, Salim Street.

\begin{abstract}
Walking represents a vital transport system for people to maintain balanced and healthy lifestyles and to improve the environmental conditions. Within a contemporary metropolitan society, other means of transport are often preferred. The presented paper aims to examine the methods of how to encourage people to walk. By organizing it into three main sections to begin with, the work of in order to investigate the nature of the metropolitan individual and the contemporary society. The second section builds on the outcomes of the first section. Hence it provides a clear rationale for the adoption of strategies that would encourage people to walk. Salim Street which is one of the important and vibrant streets inside Sulaimani city is being chosen for this study, its possibility to be a walk able street is analyzed. The third section provides practical solutions and steeps on how to promote walking among the contemporary society. then, a brief conclusion summarizes the key arguments encompassed in the presented paper and draws wider implications and recommendations for city planners to build more pedestrian friendly streets.
\end{abstract}

Copyright () 2020 Kurdistan Journal of Applied Research. All rights reserved. 


\section{INTRODUCTION}

The key rationale for the studied question can be found in the notion of sustainability and its three main dimensions - environmental, social and individual. [1]Pointed out the interlinked nature of these three dimensions by highlighting the interactions of individual effects on the social outcomes and consequently on the environmental dimension of sustainability Until lately, people were not aware of the effects of architectural concept and urban planning on human behaviors, and a great impact of physical outdoor activities. More recent studies suggest that minor details, such as the selection of materials and color, might lead to certain activity. As a result, builds on the existing body of research and aims to examine the practical ways in which the urban planners could encourage people to walk. Lack of walkability is mainly related to the urban structure design, many factors influencing the walking habits such as, the quality of the pavements, road condition, traffic, land use, street fabric accessibility and above all pedestrian safety. [2]

\section{LITERATURE REVIEW}

\subsection{Contemporary Metropolitan Society}

Both Simmel and Walter Benjamin [3] described a contemporary metropolitan citizen in terms of being over-stimulated by sensory overload which results in the fragmentary existence. While Benjamin focused on the examination of inner motives that lead to this state, Simmel emphasized the sociological aspects of the society. Overall, an individual is depicted as a product as well as defense against modern city lifestyle: "The psychological foundation upon which the metropolitan individuality is erected is the intensification of emotional life due to the swift and continuous shift of external and internal stimuli. Man is a creature whose existence is dependent on differences i.e. his mind is stimulated by the difference between present impressions and those which have proceeded. To the extent that the metropolis creates these psychological conditions - with every crossing of the street, with the tempo and multiplicity of economic, occupational and social life - it creates in the sensory foundations of mental life, and in the degree of awareness necessitated by our organization, as creature's dependent on differences, deep contrast with a slower, more habitual more smoothly flowing rhythm of the sensory mental phase of small town and rural experience." [1] The work of [4]highlights the differences between metropolitan life and a life in smaller cities in terms of an individual's perceptions as well as the crucial role of surroundings on the stimuli observed and mental states achieved. [1] , Went even further and outlined the term "cityscape" referring to the parallel nature between the land and the city. According to the author, metropolitan cities can be transformed into providing positive stimuli for it citizens, depending on the issues relating to urban design and city initiatives. In essence, while the contemporary metropolitan city suggests a high level of sensory overload for its citizens, effective "cityscape" strategies can successfully address this issue and promote a healthy life style amongst the citizens. [5] While the policies have traditionally focused on highlighting the health and personal benefits of walking and the behavioral change amongst the citizens has been anticipated, a number of constraints have been shown to moderate this relationship. According to the authors, constraints created by household responsibilities and the perceptions of normality represent the key factors that prevent people from an active engagement in walking despite their understanding of the health and personal benefits associated with this activity. In line with the work of [1],the study conducted by [5] emphasized the social and environmental factors that drive an individual's behavior. As a result, the authors concluded that an effective strategy of promoting walking needs to address the normative perceptions and lead towards the perception that walking is the logical and normal means of transport. On the other hand, [6],argument was about that 
planers as well as mayors before any design process for the city they should ask these main questions like: what type of city will flourish economically? What sort of city will keep its dwellers safe and healthy? What sort of city will sustain for the next generation? Health, wealth and sustainability are the key arguments to promote walking in our cities. To put it in a nutshell, this section highlighted the very nature of contemporary metropolitan city and metropolitan life within the city.. This parallel suggests that urban planning issues and city initiatives can successfully address the sensory overload experienced by citizens of a metropolitan city. Arguably, walking represents one of the cornerstones of a successful "cityscape" as its effective promotion depends on both the sensory perceptions of the city and the practical strategies developed by city planners. Many studies have shown that city fabric has great effect on pedestrian movements; moreover, axial map researches showed that there is a significant effect from grid pattern to urban movement. Pedestrian movement is more in complex interiors where the movement is more exploratory and less linear [7]. The following sections of the presented paper build on this notion and examine the value of walking for citizens of a contemporary metropolitan city as well as investigate the practical options available for city planners to encourage walking amongst the population of a city. . [6] Argument was planers as well as mayors before any design process for the city they should ask these main questions like: what type of city will flourish economically? What sort of city will keep its dwellers safe and healthy? What sort of city will sustain for the next generation? Health, wealth and sustainability are the key arguments to promote walking in our cities.

\subsection{Importance of Walking}

The existing body of literature on walking has associated this activity with a number of positive impacts on an individual. Overall, walkers' experience can encourage new brain cells, many studies show that physical activities stimulate positive thinking and encourage new brain cells, because staying active maintain good blood circulation and decrease the danger of many serious disease such as, stroke, heart attack, diabetes and Alzheimer's. Mental condition can be promoted by walking memorizing different routes, observing traffic signals and taking decisions [8]. Furthermore, a number of health and traffic problems can be solved by promoting walking. Due to the invasion of cars, less area is provided for walking and more spaces are dedicated to cars. Nowadays, there seems to be a lack of spaces for citizens to enjoy comfortable walking. [9] The harm of private cars cannot be ignored as this issue accounts for major environmental, health and traffic issues in cities. Also, the high demand of fuel and the extensive usage of energy can cause numerous problems in various ways. For example, burning fuel leads to $\mathrm{CO} 2$ emissions that pollute the air and damage the ozone layer. In essence, the negative effects of the overuse of cars in cities can be examined on a number of levels and undoubtedly, the encouragement of walking could at least partially address some of them. Unfortunately, the development of contemporary metropolitan cities has resulted in the lack of opportunities for walking for the citizens which often prevents them from doing so. Figure 1 (below demonstrates this ongoing problem in contemporary metropolitan cities. 


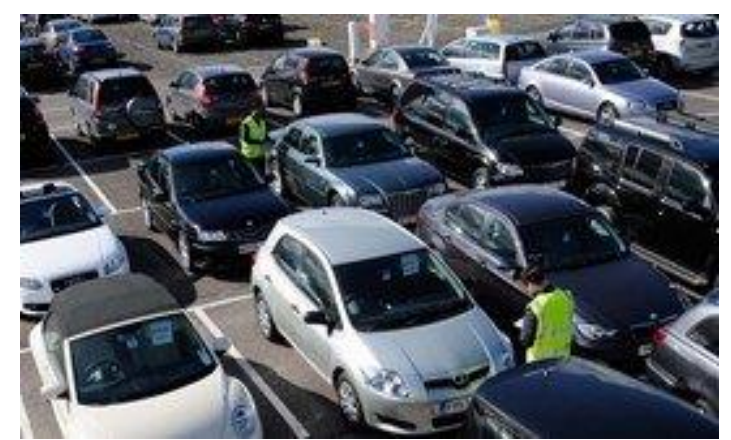

Figure 1: The rapid increase in a private car use in numerous cities around the world (ref: amonline.com).

\subsection{Ways for promoting walkability in streetscape \\ 2.3.1 Pedestrian Street Spaces}

Urban and traffic planners should pay more attention to the needs of increasing pedestrian street spaces. One of the most important basic way to promote walking is providing enough space for pedestrian to move freely without being pushed by other people all the time; and also, dimensioning the streets according to the density of the population, without neglecting the importance of having enough for people to enjoy the view [9].

\subsubsection{Attractive Scenery}

Nice scenery is important for dwellers to enjoy and have a good walking experience. In order to change human attitude about walking, the city planners should address the importance of providing attractive views by adding green area, playgrounds and designing the facades in a way to attract pedestrians as can be seen in Figure (2). Landscape designers can inspire people to walk in certain places by selecting different materials and colors. For example, people are sensitive to the pavements finishing and surface and most of them prefer even surfaces. Because while people walk unconsciously brain determine each step's height and length. Therefore, if the surface was uneven more falling accidents occur.

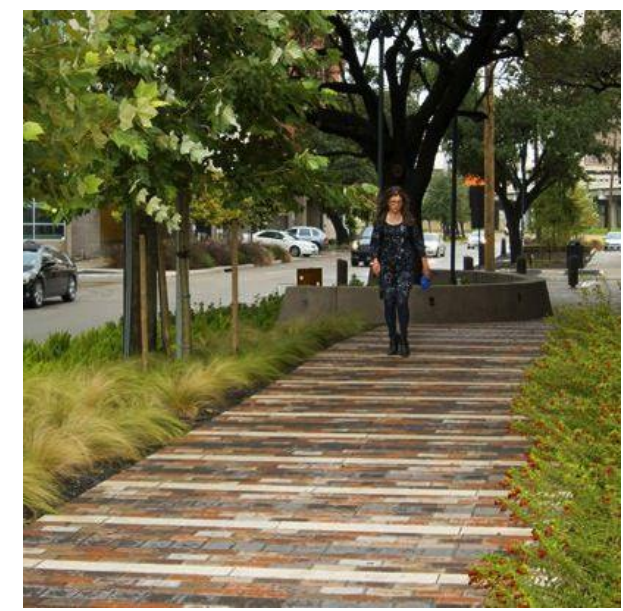

Figure 2: Attractive landscape can inspire people to walk (Ref: pintrest.com)

\subsubsection{Accessibility}

Easy access for people with special need and baby carriages are essential by providing ramps and lifts that allowed them to move from point A to B without suffering. In Jan Gehl's book [10] the author highlights the fact that "special demands for space are required by the "wheeled" walking traffic: the baby carriage, the wheelchair, the shopping cart, and so forth. Consideration for this traffic will generally necessitate more ample dimensioning than that". Furthermore, the authors also refer to how increasing the width of the pedestrian's path in 
Copenhagen had a positive effect and raised the number of pedestrians in the first year by 35 per cent, whereas the number of baby carriages increased by 400 per cent [10], Figure 15 depicts the importance of the width of the pedestrian's streets to both promote their accessibility and maximize the number of pedestrians.

\subsubsection{Orientation}

Good and effective sign-posts are to play an important role in showing people how they can get to their destination in an easy way Figure (3). Better understanding of the routes and their destination encourage dwellers to walk. Moreover, demonstrating the shortcuts and their linking to the capital routes can be helpful for walk promotion.

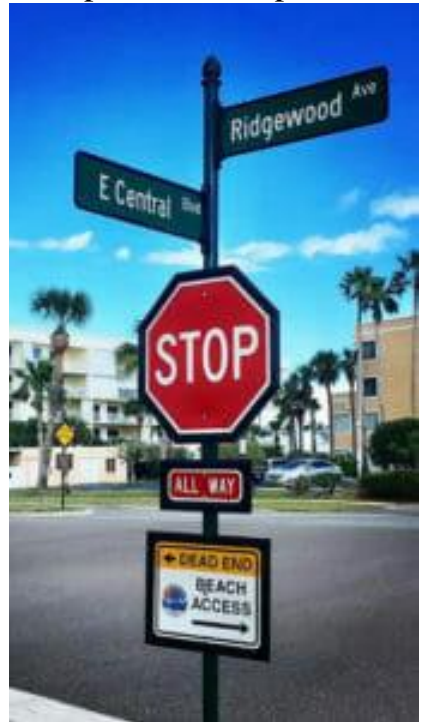

Figure3: Showing how to get to the key locations inside the cities / towns is important for pedestrians as these locations are usually used as a marker to further destinations ( Ref: https://signaturestreetscapes.com/)

\subsubsection{Weather Conditions:}

Different weather condition, such as hot, wet, windy and cold can be frustrating for pedestrian, however these problems are solvable by different solutions such as, building shade have positive impact on walkers because usually people prefer safe and intimate place to walk. Another solution is growing trees and vegetation in hot places also building the blocks in a way that blocks the wind from the pedestrian streets. For hot-dry climate shading is the best solution which can be made by different building materials and vegetation $s$ in order to minimize solar access to the sidewalks. Shading is useful for

- Minimizing the direct solar radiation absorbed by a pedestrian.

- Decreasing the heat released by the surrounding.

- Reduction in the air temperature. These aspects are depicted in Figure (4, 5 and 6) below. 


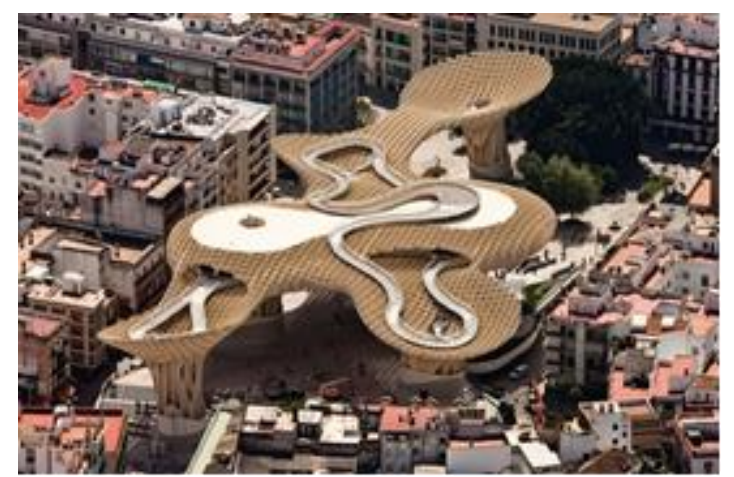

Figure 4: Shading with wood structure (Jurgen- Mayer from Seville, Spain)

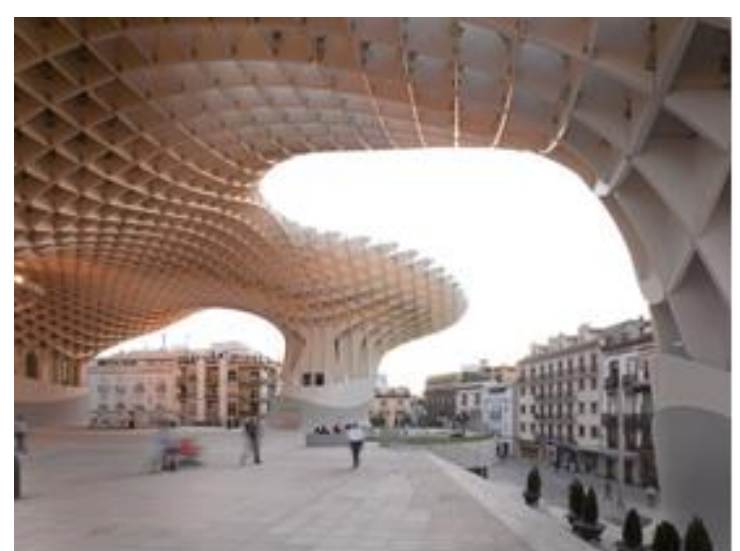

Figure 5: Jurgen- Mayer(Ref: https://www.researchgate.net/figure/Figura-2-Jurgen-Mayer-MetropolParasol-Sevilla-Composicion-realizada-a-partir-de_fig2_298654766)

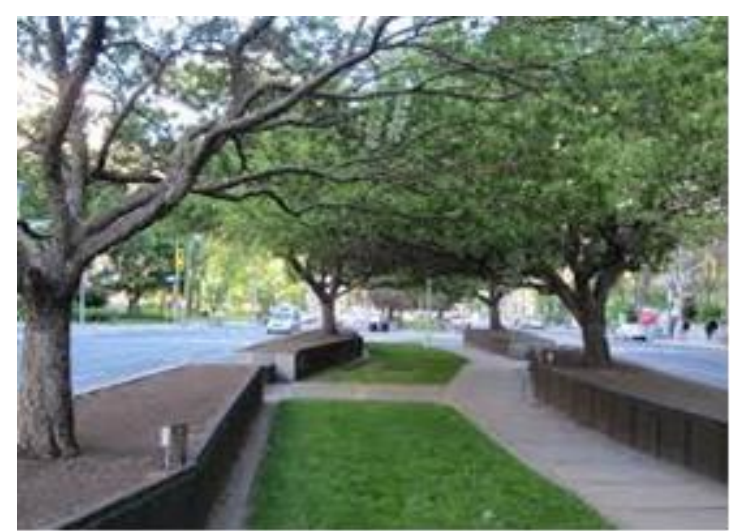

Figure 6: Trees provide shad for sunny days and provide a cooling breeze in hot-dry days

\subsubsection{Removing Obstacles}

Minimizing stairs and steps in the pedestrian streets, because in a way they are considered to represent major obstacles for people [9],It is common for pedestrians to avoid staircases and they prefer to walk longer distance instead of using the stairs (as shown in Figure 7 below). Therefore, building ramps is better for walking. In many places where both stairs and ramps exist it is obvious that the majority of people would use the ramps instead of the stairs. 


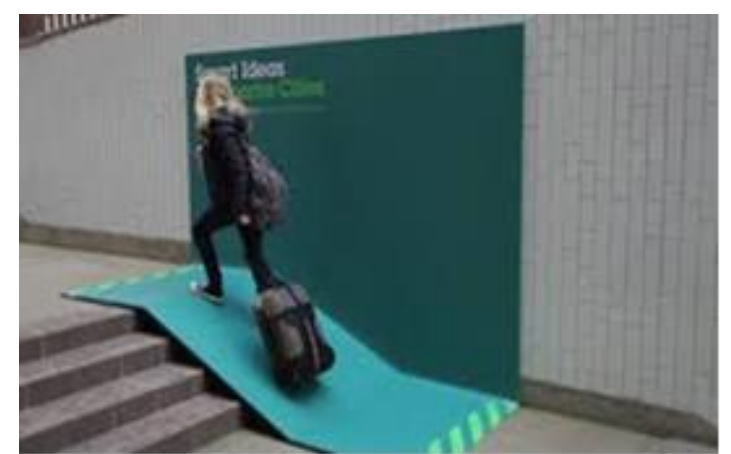

Figure 7: Pedestrians prefer ramps against stairs(Ref: https://www.creativemove.com/)

\subsubsection{Connected Networks and Street Fabric}

Better connected networks and links between the capital streets, homes, public squares, schools, shops and parks represent another vital strategy to promote walking within a city. These networks should be safe, functional, comfortable and attractive with good sign post for direction. Also, linking the route with public transportation is important for decreasing the use of private cars [11] A city' diversity, distinctiveness and richness can be characterized by its capital route which consists of five main dimensions:

- Morphology: Urban spatial setting in its static and physical form.

- Dynamism: Diversity and character of public activity patterns and their social and economic dependencies.

- Teleology: Use of public urban spaces.

- Symbolic: Meaning of public urban spaces, in particular in an associative.

- Hermeneutics: Cultural sense.

Given the prominent nature of the capital route, it tends to represent the key focus of the city authorities and attracts large portion of the developmental activity. In essence, given the fact that capital route characterizes the city in the eyes of the citizens as well as visitors, the city planners tend to focus their attention towards promoting the capital route. Furthermore, the importance of the capital route can be found in its function of a node, connecting various parts and facilities within the city.

In summary, the system of connected networks within a city predicts its potential for the introduction of strategies promoting walking. Capital route plays a central role in the development of connected networks and is commonly used as a walking zone with the prohibited access of cars into the area.

\subsubsection{Spatial Design}

Spatial designing by the planners that should provide the dwellers with most of the everyday services and facilities with a walk able distance from home such as, shops, parks, public transport stations and business parks. Better land using to minimize car usage by reducing urban sprawl and giving the priority to the pedestrian roads also closing car accessing points to these areas [10],

\subsubsection{Access and Condition}

Pedestrian's streets should be opened most of the time day and night all year long. Pedestrian streets and cycling paths should be cleared from ice and ensuring that the pavements are dry in order to prevent any injury during different weather condition. Figure 8) documents the lack of use of the pavement due to its poor condition in winter. Setting light is essential spatially during nights placing it in different positions to give the pedestrians the sense of security that allow them to walk safely [10].

\subsubsection{Lights}

During the night walking in in dark considered uncomfortable experience; therefore, adding lights is important to give secure sensation to the pedestrians generally, and like Michael R. Bloomberg said "Sidewalks should be appropriately lit at night, with pedestrian scale lighting spaced at appropriate intervals to provide the correct level of illumination". [12] 


\subsubsection{Safety}

Safety is the key elements to have an enjoyable walking experience. Adding crossintersection and zebra line, in order to cross safely from one side of the pedestrian's path to the other side of it, without been interrupted by the cars. Usually people prefer to walk continuously and safely. Restaurants, café and shops can help sidewalks [12]

stay vibrant during the day and night, keeping "eyes on the street," as Jane Jacobs said.

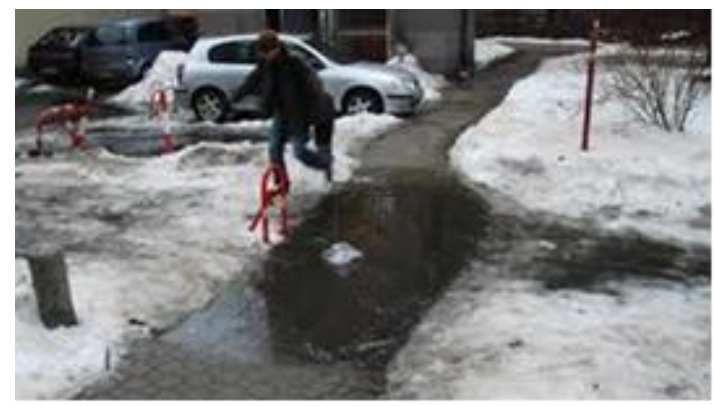

Figure 8: People avoid wet and slippery pavements. (Ref: jeziorki.blogspot.com)

\section{Research Aims}

The purpose of this study is to examine the walkability in Salim Street and outline the challenges and problems for enhancing its walkability. Aim for this research is to highlights several policy recommendations for improving the current pedestrian infrastructure and gives logical solutions to make Salim Street more walkable- oriented Street.

\section{CASE STUDY and RESEARCH METHOD}

\subsection{Case study (Salim Street)}

Salim Street considered one of the vibrant capital roots in Sulaimani city crossing the city nearly from the middle as can be seen in Figure (9 and 10), which creates a major urban transect, that has pedestrian flow with strong, flow indicators - mass, direction and speed, for most of the day/night hours.

Overall, Salm Street determines the urban interfaces with numerous public spaces, civic and public buildings and thus provides the basis for the examination of tourism, commerce, retail, administration, cultural, residential and transportation opportunities. Typically, the capital route tends to be between 1,000-3,000 meters long and takes $2-3$ hours of walking time. It provides residents and visitors of a city with significant urban diversity and characterizes the image of the city. 


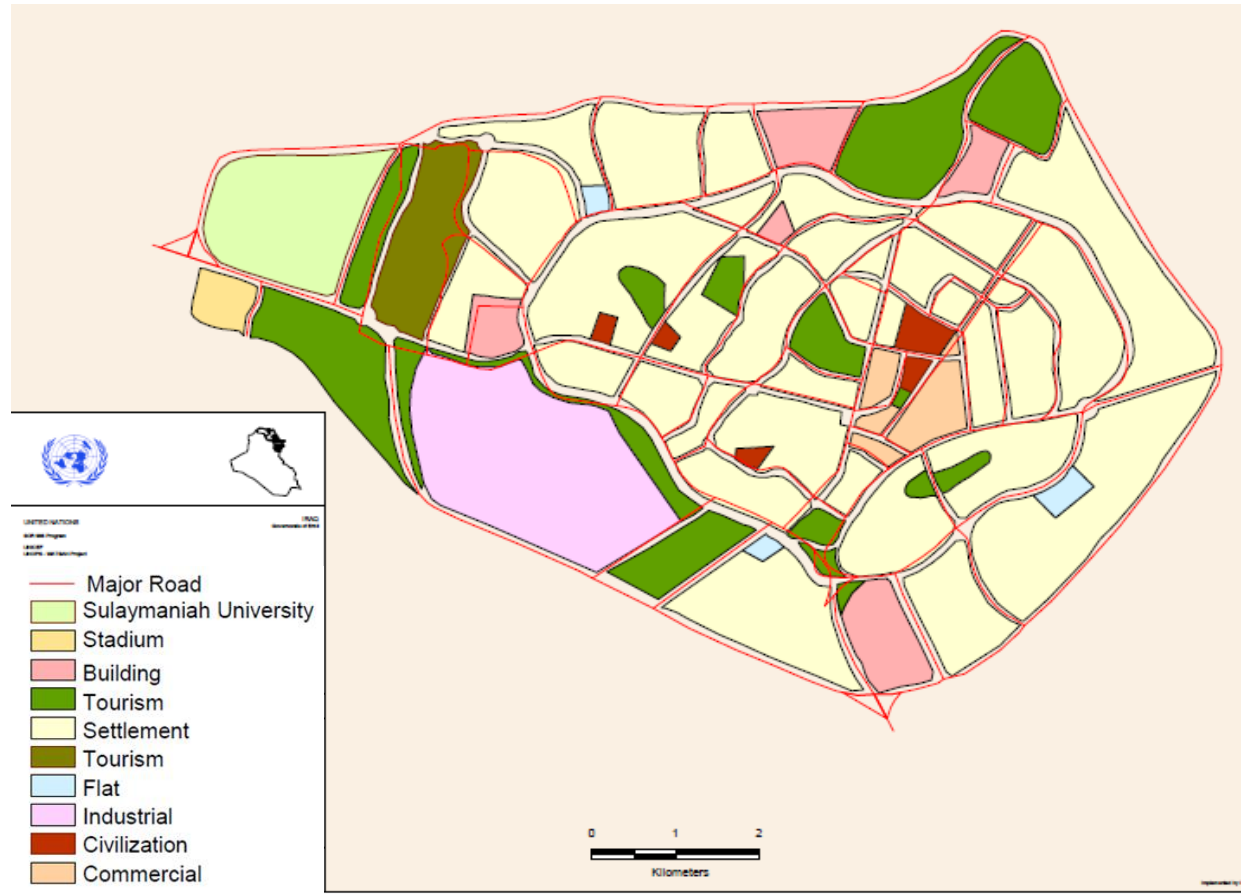

Figure 9: Sulaimani city map. (Ref: ecoi.net ,2017) https://www.ecoi.net/en/document/1160964.html

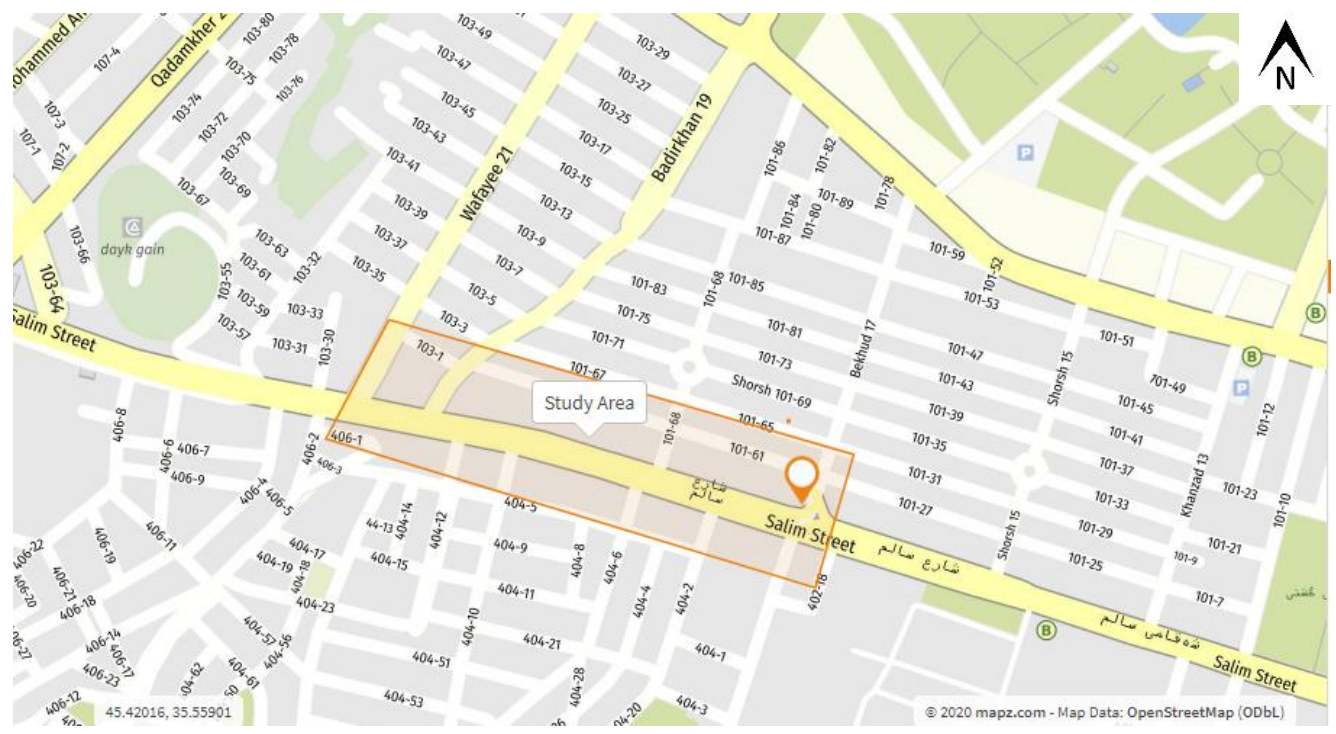

Figure 10: The Study area within Salim Street (Ref: Mapz.com, accessed May 2020) https://www.mapz.com/export/398915\#

Salim Street starts from Sarchnar cross, and ends with the beginning of Mawlawi Street as Illustrated in Figure (11). It is about $4.5 \mathrm{~km}$ distance. However, our case study starts from Khasraw Khal Bridge until Shahid Raoof Bug Under-path and the distance is about $2 \mathrm{~km}$. 


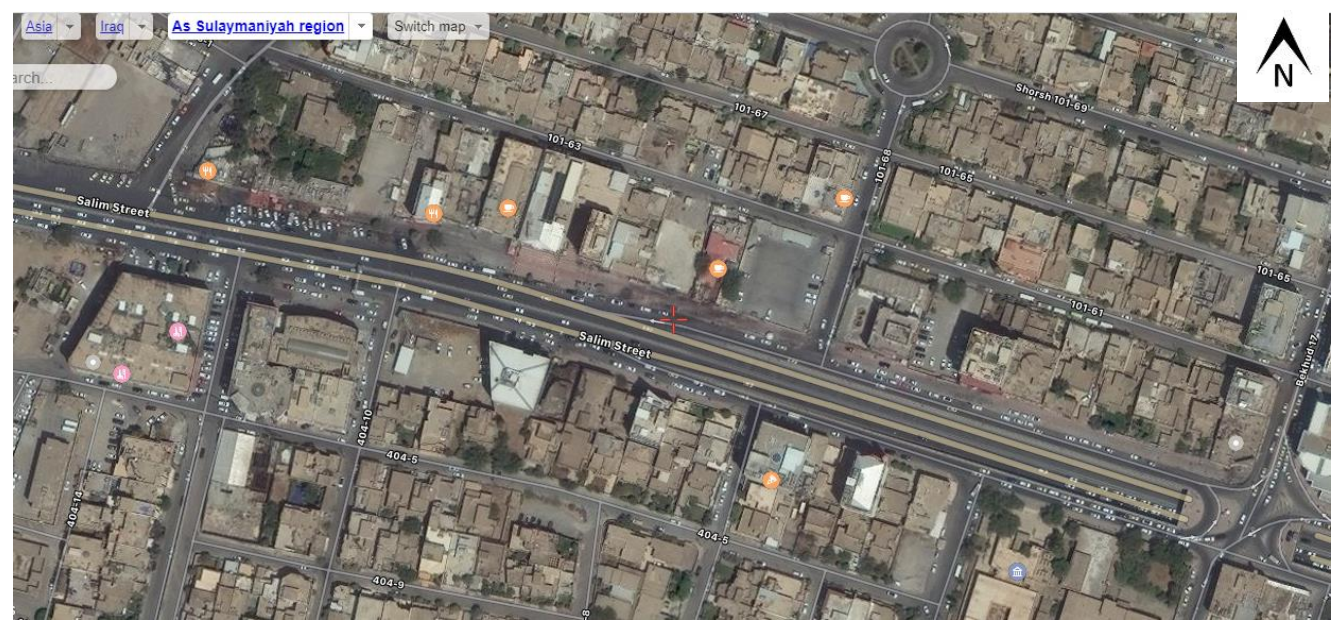

Figure 11: Satellite image of Salim Street (Ref: satellites.pro accessed May 2020) https://satellites.pro/Iraq_map\#35.558712,45.424100,18

Salim Street is very important for Sulaimnai City as most of the anniversary events such as Nawroz and New Year festivals take place in this street as seen in Figure (12). During the events the street will be car free zone, only pedestrian are allowed to enter the street, however, like many other capital streets in Sulaimani city Salm street is not flawless it has many problems, such as traffic jam, uneven surface, lack of walkability, lack of safe crossing and many other issue as shown in the Figure $(13,14,15$ and 16), which we will highlight on them in the next paragraphs.

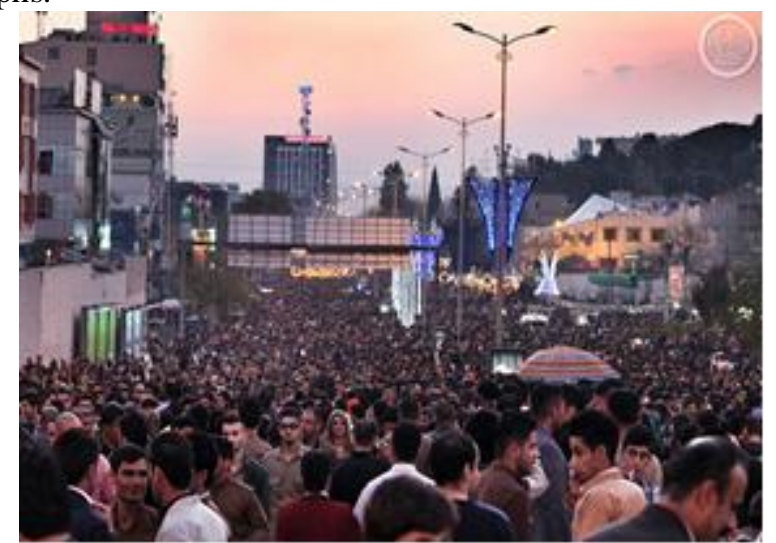

Figure 12: Nowroz Festival in Salim Street (Ref: the researcher)

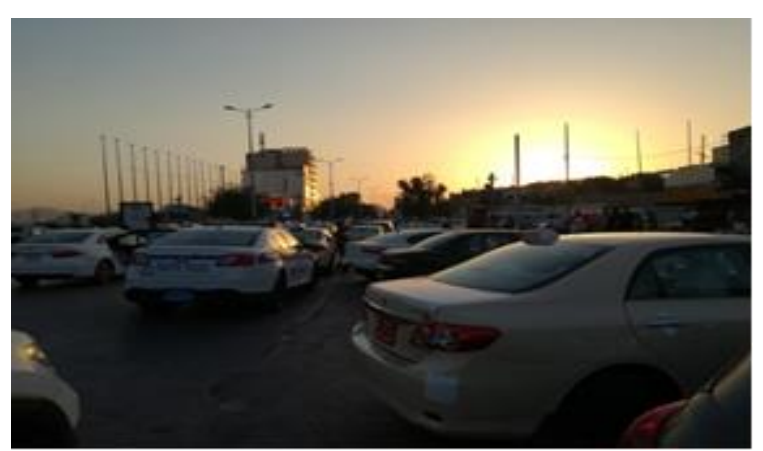

Figure 13: Lack of parking Space in Salim Street (Ref: the researcher) 


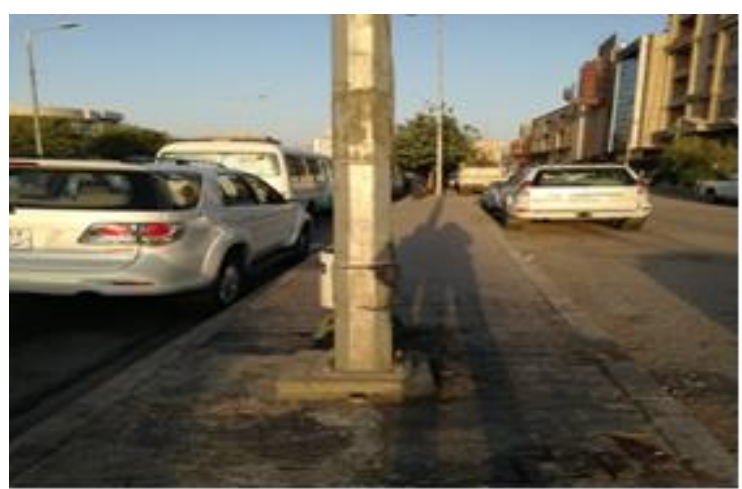

Figure 14: Obstacles in the pedestrian paths that left no space for walking (Ref: the Researcher)

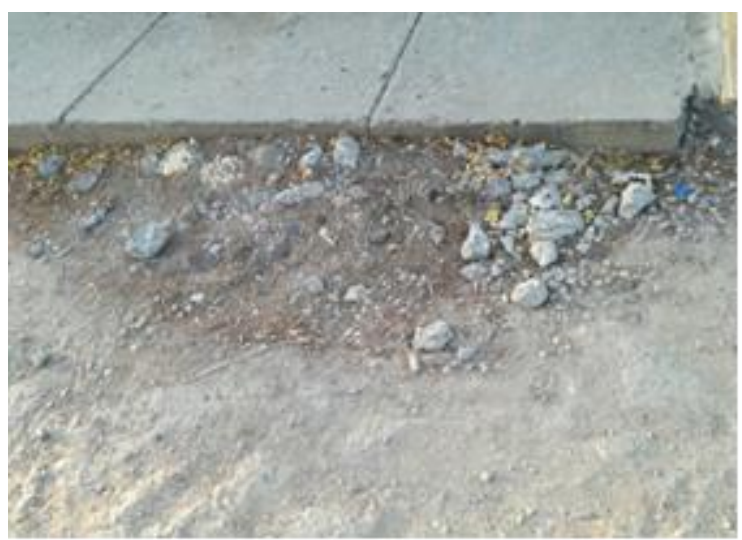

Figure 15: Unfinished surface of the pedestrian paths (Ref: the Researcher)

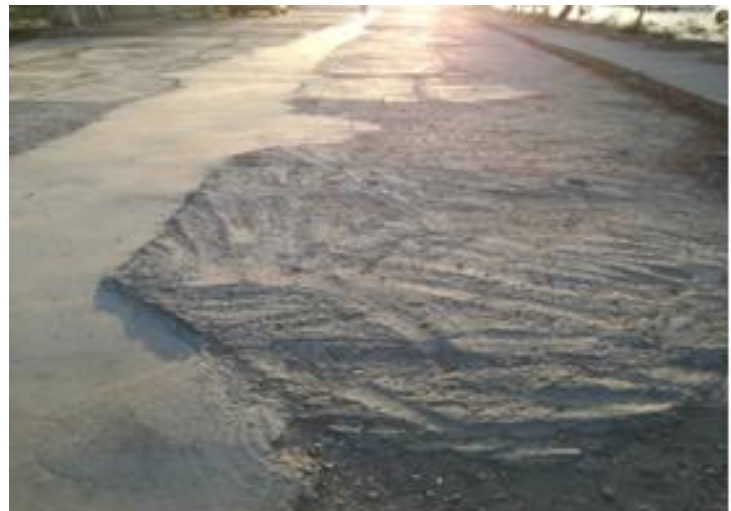

Figure 16: Uneven pavements are less accessible for disables and baby carriages (Ref: the Researcher)

On the other hand, Salim Street you can observe many bus roots and many bus stations, but few people ride them due to the poor condition of the buses and uncomfortable experience during the journey. Moreover, according to the observations done by the authors, the only public transportation exist in the street was bus lane, with the absence of tram or train lanes on it, it is problematic for city dweller to use only buses to get to their destinations, The side streets around the main streets previously was constructed in order to reduce traffic jam on the Salm Street, on contra, the results were more traffic on both streets and less pedestrian paths, planners should design for people and spaces not for cars and traffic Figure (17). 


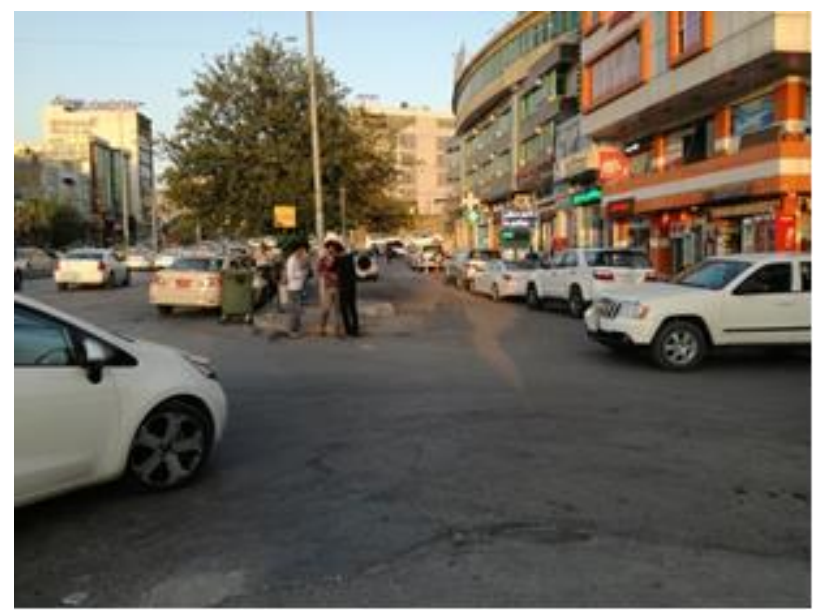

Figure 17: Side streets in Salm Street (Ref: the researcher)

There are some plots located on Salim Street, currently they are empty and not used for any obvious projects, but they might be useful for futuristic design proposals Figure (18-19),

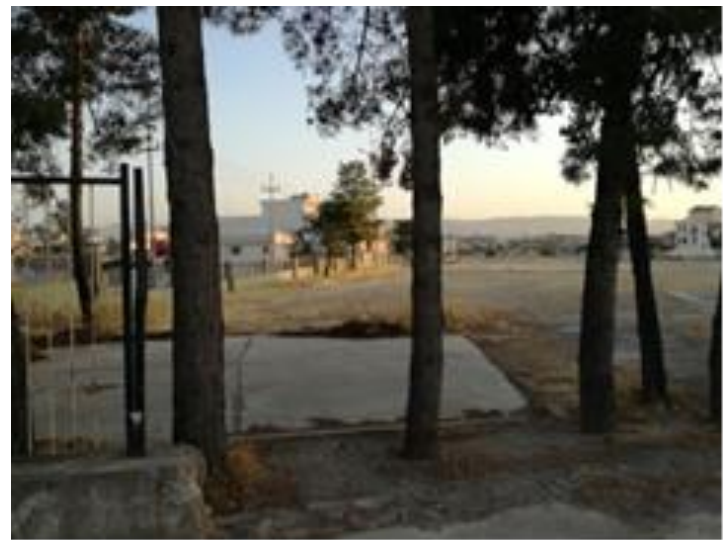

Figure 18: empty plot located on Salim Street (Ref: the researcher)

Lately a few traffic light were inserted in the street for more safer crossing for pedestrian, and also to give pedestrian more right to the street, however, many don't obey traffic regulations and choose to cross the street without waiting for the green light, which makes it more unsafe journey for both car users and pedestrian Figure(19-20). Moreover, along Salim Street only three traffic lights were inserted for pedestrian that makes it for every $1.5 \mathrm{~km}$ there is only one traffic light, according to the street users this number could not cover the demand for this vibrant and busy street.

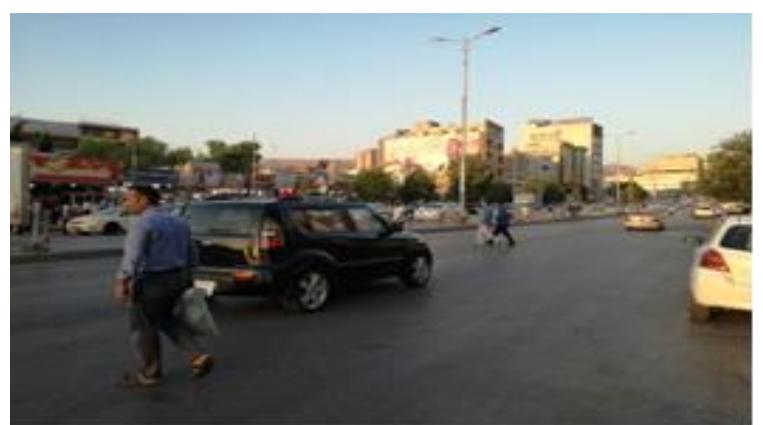

Figure 19: Unsafe Street crossing for pedestrian, with the absence of traffic regulation in Salim Street (Ref: the researcher) 


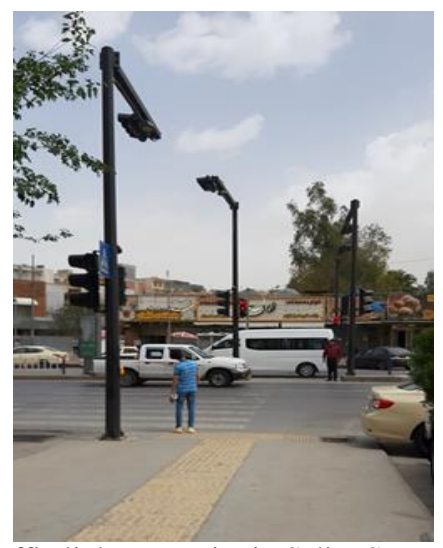

Figure 20: Adding traffic lights on point in Salim Street (Ref: the Researcher)

In Saholaka part of Salim Street, a few buildings were demolished for the sake of building more space for car parks, which can be seen in figure $(21-22)$. On the other hand, some shop owner stated that they had to change the type of their business due to car invasion on the street and they were not able to keep their business because of the number of car parking along the street.

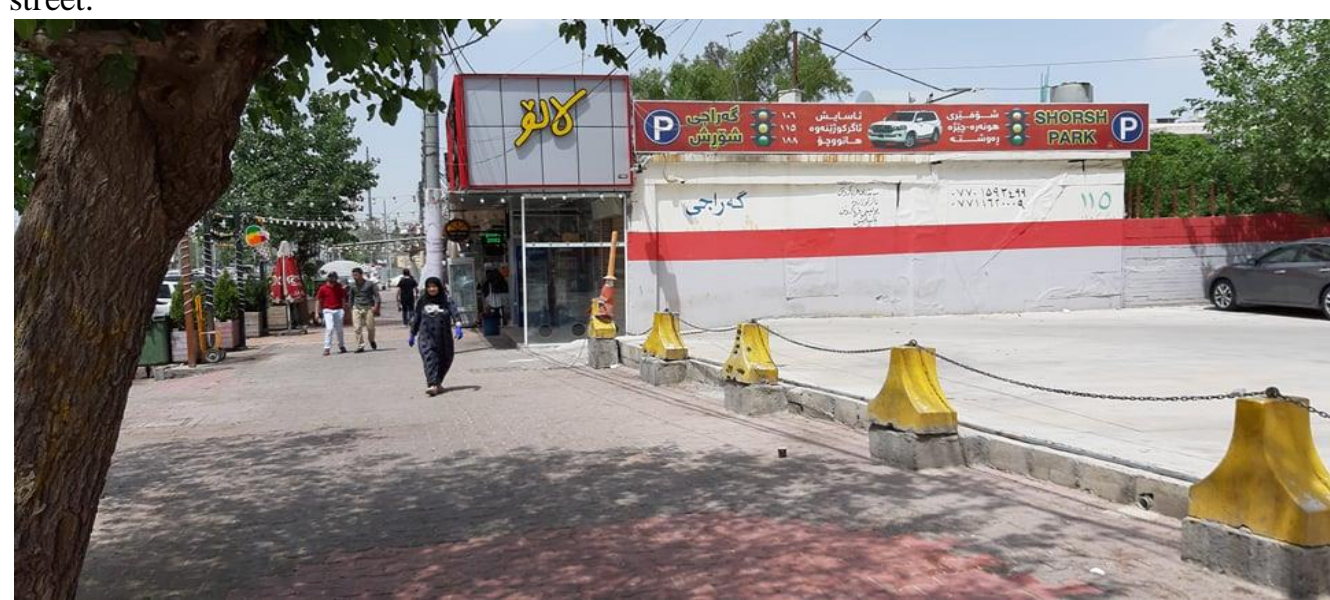

Figure 21: Car park space in Salim Street (Ref: the Researcher)

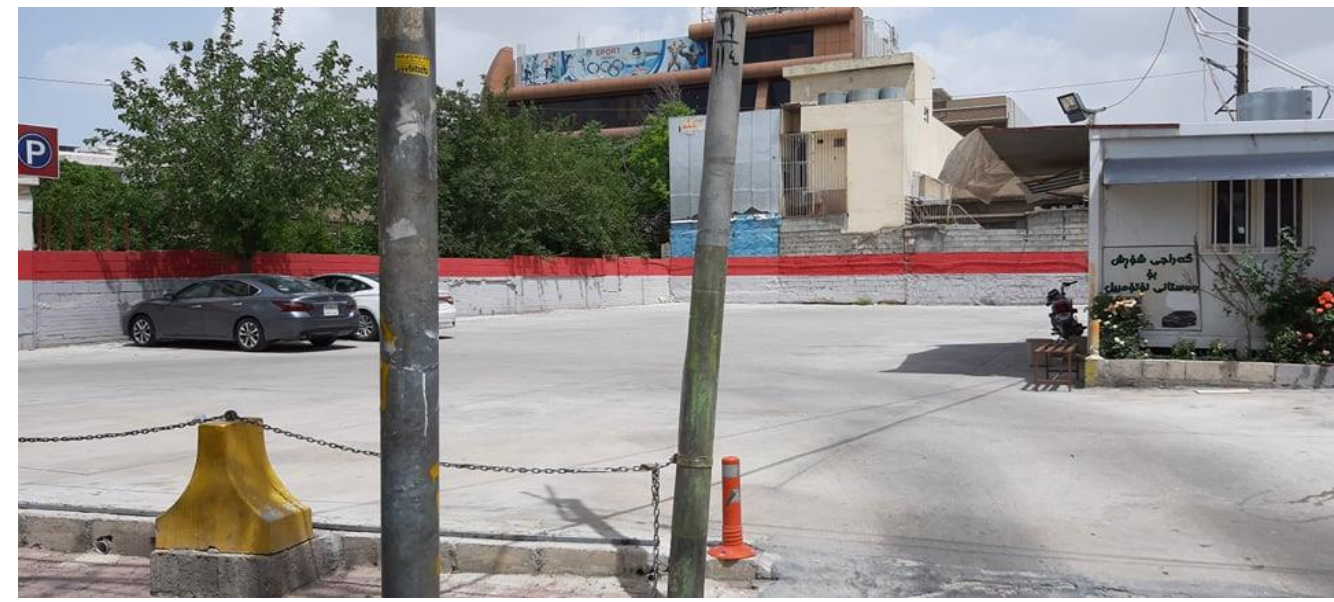

Figure 22: Car Park in Salim Street (Ref: the Researcher) 


\subsection{Research Method}

In order to determine walkability in Salim Street firstly, understanding the physical features that affect it is essential; therefore, this study conducted both quantitative and qualitative approaches for collecting data. Quantitative data were collected by a questionnaire on the other hand; qualitative data were collected via interviews and direct observation of the street. An interview including open-ended questions was conducted with 20 shop owners who are working in Salm Street. They were asked questions about the strength, opportunity, weakness and threat of this street on the basis of the Environment, Road Attributes and Walking Environment. These criteria are crucial because environment managed with less tangible but nevertheless important features of the road that ought to be taken under consideration when surveying the pedestrian environment. Moreover, road attributes as the condition, characteristics and dimensions of a roadway that can have a direct impact on the quality of the pedestrian environment. consisted of walking environment and appeared that the components of a street and generally the image of the street are contributed in assessing the pedestrian environment. [13]

\section{RESULTS AND DISCUSSION}

\subsection{Questioner}

Questioner has been done about the Salim Street (100 person) participated and answered the questions with different ages, and their answer are used for making charts depending on their age, two various categories were chosen first with age (15-30) years the other peoples that their ages between (30-60) years as the majority of pedestrian on the Salm Street are about these ages. Moreover, all of them answered (5) questions as shown below: Nearly $35 \%$ of the people with age (30-60) years they said that they feel pleasant while they are walking on the pavement chart (1). However, the result for other ages is totally different, as they mentioned the bad condition of the pavement when they have been asked about their answer.

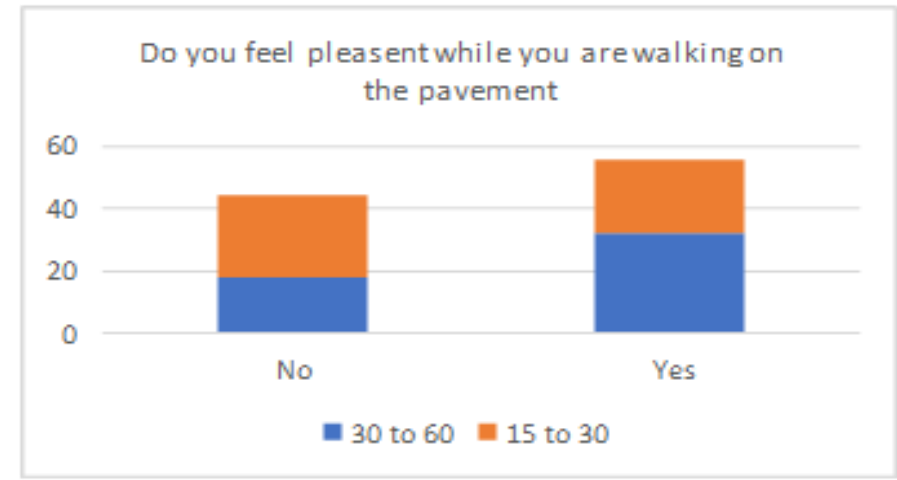

Figure 23: Shows people's feeling while walking on the pavement.

Figure (17, 18 and 19) illustrate the present condition of the Salim Street and the people's answer proved that the crosswalks are not helpful especially for people with special needs and baby carriage. 


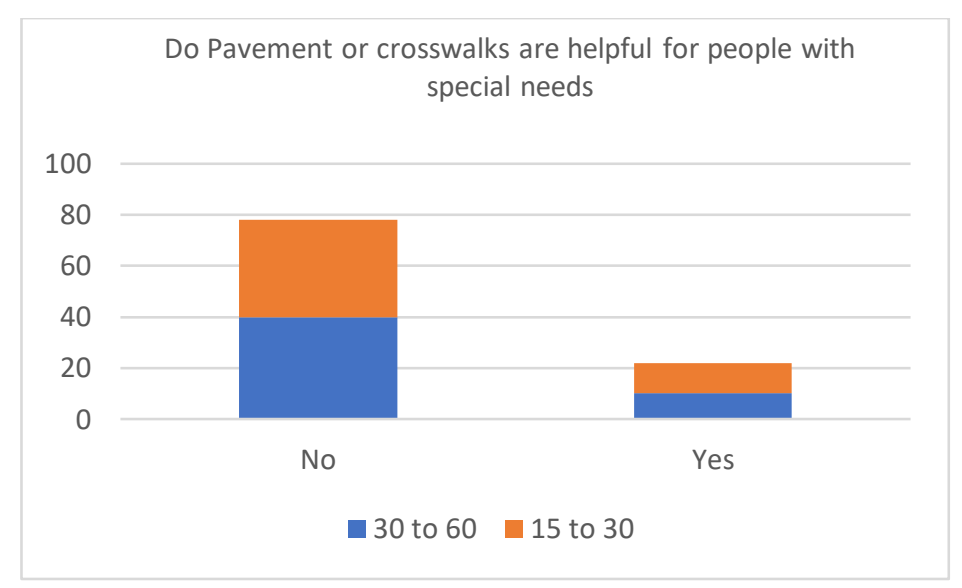

Figure 24: How pavements and crosswalks help people with special needs.

The answered of the questions 3 is shown in the chart below illustrates that the question that most people agree on it is that crossing the Salm Street is not easy and not safe, it is important to take this point with consideration. Even though lately a few traffic light were inserted for safer crossing, but not many pedestrian follow the regulations and use them. On the other hand, Salim Street is about $4.5 \mathrm{~km}$ and there are only three traffic lights for pedestrian which is not enough according to the interviews with the people whose using the street.

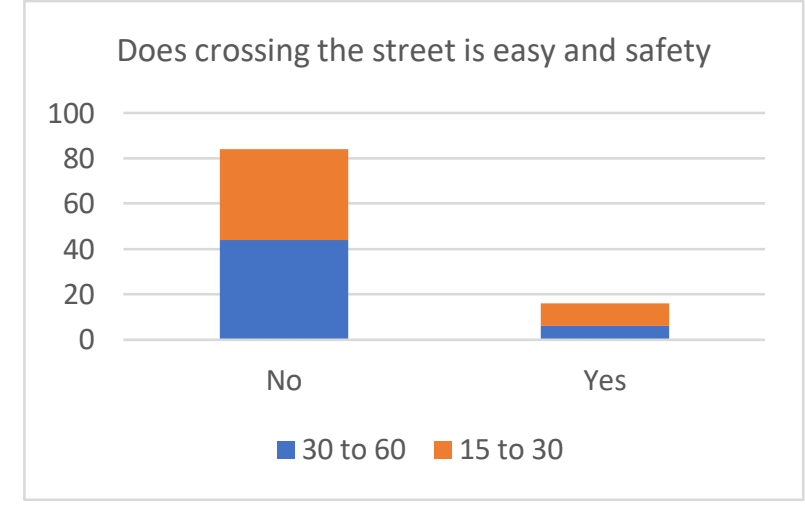

Figure 25: Dose crossing the street is easy and safety.

More than $\% 80$ people in the different range of ages answered that the numbers of cars that are parking on the street create an obstacle for the people to cross the street chart (4), and this answer should be considered while trying to make the part of this street as a pedestrian. 


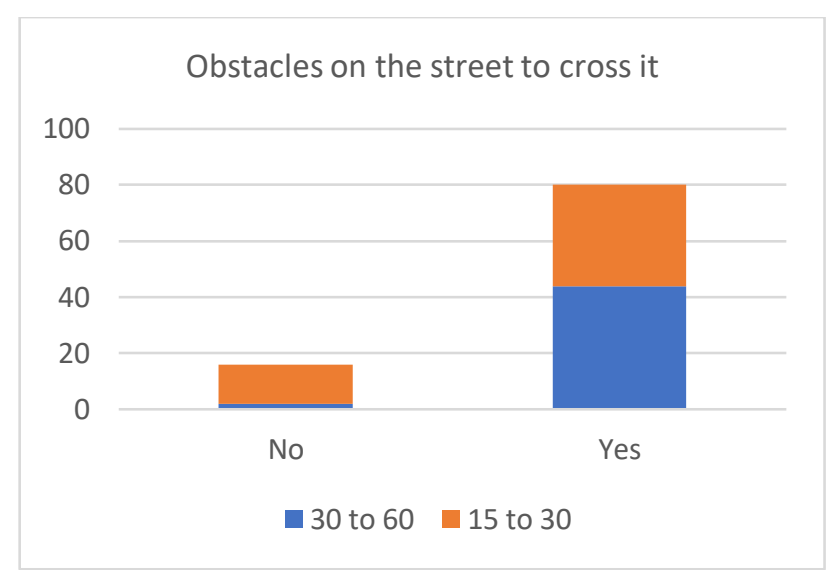

Figure 26: the effect on the parking on the crossing.

Chart number (5) explains that the most people of both categories find that it is more appropriate to design a part of the Salm street as a pedestrian road.

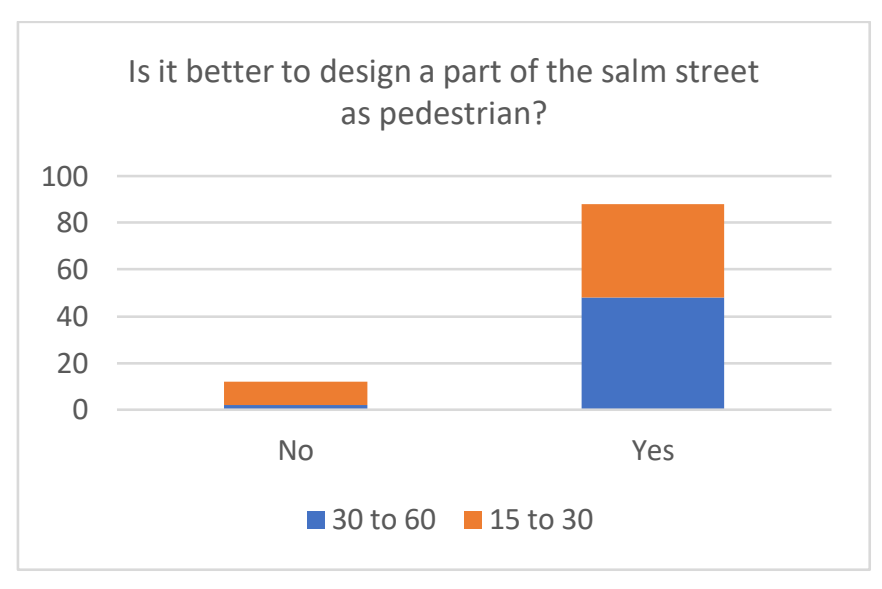

Figure 27: people's answer about designing Salm Street as a pedestrian.

\subsection{SWOT ANALYSIS}

Tables (1,2 and 3) explains the summary of these interviews. Table (1) shows the items related to the environment that some weaknesses connected to traffic jam and air pollution are mentioned. However, in table (2) most of interviewees stated weaknesses regarding to road attribute such as, poor street condition, maintenance service and car parking problems on the street. Furthermore, not having appropriate sidewalks, lack of greenery, un sufficient pavement width for pedestrian and lack of street furniture with lack in providing street pedestrian with sufficient amenities such as public toilets are mentioned by almost all the interviewees.

There are some strength points that are declared by shop owners when they asked about walking environment for example, providing different type of street food, having sufficient lighting with combination of activities and places such as, shops, cafés and restaurants with sufficient lighting, table (3). 
Table 1: Issues correlated to Environment

\begin{tabular}{|l|cl|}
\hline Strength & $\bullet$ & $\begin{array}{l}\text { Mixed used road that works as a major network links most of the city } \\
\text { together }\end{array}$ \\
\hline Weakness & $\bullet$ & Traffic jam during both day and night \\
\hline Opportunity & $\bullet$ & Crossing Sulaimani city from the middle \\
\hline Threats & $\bullet$ & Air pollution due to car invasion \\
\hline
\end{tabular}

Table 2: Issues correlated to Road attribute

\begin{tabular}{l|cl}
\hline Strength & The maximum allowed speeds is $\mathbf{5 0} \mathbf{~ k m} / \mathbf{h o u r}$ \\
\hline Weakness & $\bullet$ & Poor street condition \\
& - & High density of car traffic and car domain the street \\
& - & Poor maintenance service \\
& - & Few traffic control at the intersections and cross walks \\
& & Lack in obeying the regulation when it comes to using the street by both \\
& & drivers and pedestrian. \\
\hline Opportunity & $\bullet$ & Considered as the capital rout of Sulaimani City \\
\hline Threats & $\bullet$ & NA \\
\hline
\end{tabular}

Table 3: Issues correlated to walking Environment

\begin{tabular}{|c|c|}
\hline Strength & $\begin{array}{ll}\text { - } & \text { Named by the shop owners as best place in Sulaimani city } \\
\text { - } & \text { Providing different type of street food } \\
\text { - } & \text { Sufficient lighting } \\
\text { - } & \text { A diverse combination of activities and places, such as shops, cafés and } \\
\text { restaurants }\end{array}$ \\
\hline Weakness & $\begin{array}{l}\text { - } \text { Uneven sidewalks } \\
\text { - } \quad \text { Lack of greenery and trees } \\
\text { - } \quad \text { Lack of sufficient pavement width for pedestrian } \\
\text { - } \quad \text { Lack of street furniture and shelters for different weather condition } \\
\text { - } \quad \text { In some locations trees located in the middle of the sidewalks } \\
\text { - } \quad \text { Lack in providing street pedestrian with sufficient amenities such as } \\
\text { - } \quad \text { Noblic toilets }\end{array}$ \\
\hline Opportunity & - $\quad$ Convenient site to promote walkability \\
\hline Threats & - $\quad$ Unsafe crossing \\
\hline
\end{tabular}

\section{CONCLUSION}

The aim of this paper is to critically investigate the methods of how to promote walking amongst the contemporary society and to provide practical ways in which the urban planners could encourage people to walk. The benefits of walking can be found in the area of health and a notion of a sustainable and livable environment. Building on the extensive review of the 
existing body of research on the studied topic, the paper provided a firm rationale for the need to promote walking in Salim Street. Furthermore, a number of practical recommendations have been summarized which are expected to provide guidance for the city planners in pursuing such initiatives.

Despite the interest of academics and urban planners in this phenomenon, the contemporary metropolitan society tends to prefer other means of transport due to their convenience.

According to the questionnaire which investigated by the authors, and the target were asking Salim Street pedestrians which the range of their age were about (15-60) years old, which they were asked some essential question about the current street situation and their vision for any futuristic developments. Most of the pedestrian answered that they are struggling during walking on the pavements due to its bad condition and uneven surface also they were concerned about crossing the street as they find it not safe enough even though lately a few traffic lights were inserted to Salim Street but still many people don't obey the regulation properly. On the other hand, lack of enough parking spaces was another concern by the pedestrian as they described as major obstacle.

Furthermore, making Saholaka part of Salim Street car free zone during night time can be a convenient solution for the uncomfortable traffic jam to make more room for pedestrian, moreover, as a result of the questionnaire which was done by the authors, majority of the participant preferred Saholaka part of Salim Street to be only for pedestrian rather than to be dominated by cars.

Many practical solutions for encouraging walking inside the city are explained in the previous sections that could be applied in the Salim Street in which increasing pedestrian street spaces can help pedestrian to move freely. Providing attractive views by adding green area, playgrounds and designing the facades in a way to attract pedestrians is also a suitable solution for the chosen street. Furthermore, Easy access for people with special need and baby carriages is one of the most important points that need to be considered by urban planner with showing people how they can get to their destination in an easy way. In a hot and dry climate, as in our country providing shading for people is essential and can be achieved by growing trees, vegetation and building shade.

\section{REFERENCE}

[1] G. F. Giusti, "Mapping the Experience of the Walker: A Spatio-Dynamic Method of Designing a Responsive Environment for the 21st Century Pedestrian Culture," in walk21-VI "Everyday Walking Culture”, Zurich, 2005.

[2] N. Al-Qemaqchi and W. Abdulla, "The Effect of Walkability on the Sustainable University Campuses A comparison between the old and new campuses of Sulaimani University," in 7th Engineering and 1st International Scientific Conference College of Engineering , Baghdad, 2017.

[3] G. Gilloch, Mythe and Metropolis: Walter Benjamin and the city, Oxfordshir: Polity Press, with Blackwell publishers Ltd, 1996.

[4] G. Simmle, The Metropolis and Mental life, Newyork: Free Press, 1950.

[5] G. C. Pooley, D. Horton, G. Scheldeman, C. Mullen, T. Jones, M. Tight, A. Jopson and A. Chisholm, "Policies for promoting walking and cycling in England:A view from the street," Transport policy vol.27, pp. 66-72, 2013.

[6] J. Speck, Walkable city, New york: Farra, straus and Giroux, 2012.

[7] B. Hillier, "A theory of the city as object," Urban design international, pp. 7(3-4), 153-179, 2002.

[8] A. Association, "Stay Physically Active," 2018. [Online]. Available: https://www.alz.org/helpsupport/brain_health/stay_physically_active. [Accessed 1 April 2019].

[9] J. Gehl, Cities for people, Washington, DC: Island press, 2010.

[10] J. Gehl, Life between buildings, Washington, DC: Island press, 2011.

[11] L. Steg, "CAN PUBLIC TRANSPORT COMPETE WITHTHE PRIVATE CAR?," IATSS research, pp. vol.27, Issue 2, pp. 27-35, 2003. 
[12] M. R. Bloomberg, A. Burden , D. Burney, T. Farley and J. Sadik-Khan, "Active Design: Shaping the sidewalk experience," New York City Department of City Planning, City of New York, 2013.

[13] H. Khder, S. Mousayi, T. Khan and Hayat, Impact of street's Physical Elements on walkability : a case of Mawlawi street in Sulaymaniyah,Iraq, Malaysia: Faculty of Built Environmnet, Universiti Teknologi, 2016, pp. V3(1), 18-26. 